\title{
Por uma ética do cuidado na psicanálise da criança
}

\author{
Rafaela Mota Paixão França ${ }^{a, b^{*}}$ \\ Zeferino Rocha ${ }^{a}$ \\ aUniversidade Católica de Pernambuco. Recife, Pernambuco, Brasil \\ ${ }^{b}$ Centro de Pesquisa em Psicanálise e Linguagem. Recife, Pernambuco, Brasil
}

Resumo: Ao refletir sobre a função do cuidado na constituição psíquica, este artigo discute os aspectos fundamentais para se pensar a clínica psicanalítica com crianças, marcada por um exercício ético. 0 estilo clínico de Winnicott e de Ferenczi, tomado como referência, favorece a proposição de que a dimensão intersubjetiva mostra-se como um elemento central à ética do cuidado em psicanálise, podendo contribuir para movimentar as práticas de cuidado na infância.

Palavras-chave: cuidado da criança, ética, psicanálise da criança.

A conhecida Fábula de Higino (poeta latino, 50-139d. C.), também conhecida como Mito do Cuidado, narra o papel do cuidado na estruturação do homem, aproximando-nos de uma leitura poética sobre a constituição da humanidade. Conta-se que:

Cuidado, ao atravessar um rio, viu uma massa de argila, e, mergulhado em seus pensamentos, apanhou-a e começou a modelar uma figura. Enquanto deliberava sobre o que fizera, Júpiter apareceu. Cuidado pediu que ele desse uma alma à figura que modelara e facilmente conseguiu. Como Cuidado quisesse dar o seu próprio nome à figura que modelara, Júpiter o proibiu e ordenou que lhe fosse dado o seu. Enquanto Cuidado e Júpiter discutiam, apareceu Terra, a qual igualmente quis que o seu nome fosse dado a quem ela dera o corpo. Escolheram Saturno como juiz e este equitativamente assim julgou a questão: "Tu, Júpiter, porque lhe deste a alma, Tu a receberás depois de sua morte. Tu, Terra, porque lhe deste o corpo, Tu o receberás quando ela morrer. Todavia, porque foi Cuidado quem primeiramente a modelou, que ele a conserve enquanto ela viver. E, agora, uma vez que, entre vós, existe uma controvérsia sobre o seu nome, que ela se chame Homem, porque foi feita do humus [da terra]. (Rocha, 2011, p. 75, tradução do original)

Nesta fábula-mito, a natureza do cuidado é tomada como aquela que molda a existência humana, sendo mais importante, inclusive, do que outros elementos na origem do homem, como a alma e o corpo. Enquanto personagem, Cuidado é criativo

\footnotetext{
Autora correspondente: rafampaixao@hotmail.com

1 Seguimos a referência de acordo com a formulação proposta por Rocha (2011).
}

ao transformar a argila em uma figura humana, tendo recebido a incumbência de conservar o Homem ao longo de sua vida. A beleza desta fábula reside na simplicidade de apresentar os aspectos que compõem e participam da nossa existência. Nela, Cuidado não apenas molda o Homem, como o acompanha pela vida inteira.

Da filosofia à psicanálise, encontramos importantes elaborações sobre a natureza do cuidado. Podemos citar, na filosofia, por exemplo, Heidegger e Foucault, pelas formulações para uma ontologia do cuidado e pela problematização do cuidado de si, respectivamente. Na psicanálise, além da obra freudiana, temos a referência dos trabalhos psicanalíticos contemporâneos, entre ao quais destacamos: Kupermann (2008), Figueiredo (2009), Rocha (2011) e Dunker (2011), que retomam o tema cuidado discutindo sua função estruturante, tal como proposto por Freud, e teorizam sobre o que se tem chamado clínica do cuidado ao repensarem a prática psicanalítica e o papel do psicanalista.

Neste trabalho, nosso objetivo é refletir sobre a função do cuidado na clínica psicanalítica de crianças na contemporaneidade. Longe de percorrer a epistemologia filosófica do cuidado ou sua metapsicologia na psicanálise, por entender que essa seria uma tarefa extensa para o momento, destacamos aqui as dimensões do cuidado que participam da constituição subjetiva, com vistas a uma reflexão sobre os aspectos fundamentais para pensarmos a clínica psicanalítica estendida a um exercício ético.

Partimos da consideração do papel do cuidado na emergência do sujeito tal como pensado pela perspectiva psicanalítica, principalmente winnicottiana, pela importância que conferiu ao ambiente no processo de desenvolvimento das crianças. Em seguida, desenvolvemos o que estamos chamando de ética do cuidado em psicanálise, tomando como referência as noções de empatia e hospitalidade propostas por Sándor Ferenczi (2011b). Iremos nos 
restringir ao essencial de suas formulações, tomando-as apenas como mote para pensar em uma clínica do cuidado com crianças para, por fim, apresentar a proposição de que a dimensão intersubjetiva mostra-se como um elemento central às práticas de cuidado na infância.

\section{Uma leitura psicanalítica do cuidado}

Sabemos que as dimensões do cuidado atravessam os indivíduos desde muito cedo, participando e contribuindo para a constituição da subjetividade. A marca da presença do outro, portanto, transforma o cuidado em um elemento fundamental no processo de subjetivação, conferindo-lhe uma função estruturante na vida, posto que a maneira como somos recebidos e reposicionados no mundo guarda relação direta com as formas de ser e existir.

Em Inibições, Sintomas e Angústia (1969/1926), Freud afirma que o bebê sofreria de um desamparo psíquico correspondente a seu desamparo biológico. Para ele, o bebê está unido aos cuidados da mãe e será, sobretudo, dessa união que advirá a vida subjetiva. O estado de desamparo, portanto, foi apontado por Freud como expressão da condição inicial de fragilidade do homem em relação ao mundo e é explicado tomando como referência a condição de prematuridade do ser humano. Essa condição de dependência inicial apresenta, implicitamente, o lugar que o cuidado assume na constituição física e psíquica do homem, uma vez que resulta da maneira como seremos recebidos e apresentados ao mundo nos primeiros tempos de vida - o que nos permite afirmar que o cuidado é uma condição de possibilidade para a aquisição do processo de subjetivação.

Para Freud, a presença de um outro é fundamental não apenas por garantir as funções vitais (fome, sede), mas, por favorecer a constituição da vida afetiva. $\mathrm{O}$ cheiro materno, o acalento no corpo de quem cuida promovem além de satisfação das funções de preservação, a proteção e o cuidado necessários a uma estruturação subjetiva fortalecida frente às experiências aflitivas.

Na obra de Winnicott, por sua vez, a descrição do cuidado é marcada pelo ambiente e pela presença suficientemente boa exercida pelo outro na constituição psíquica. Para o psicanalista britânico, o protótipo da experiência de cuidar é a relação inicial do bebê com sua mãe, caracterizada pela condição de dependência do bebê e pela disponibilidade materna. Nesse sentido, cuidar implicaria, em princípio, uma posição de entrega ao outro, que em estado de preocupação explícita, tende a favorecer as primeiras adaptações do bebê ao mundo. Sobre isso nos diz Winnicott (1955/2005, p. 127):

A psicanálise preocupa-se (e assim deve ser) primordialmente com a satisfação das necessidades instintivas (o ego e o id) mas, nesse contexto, estamos mais interessados na provisão ambiental, que torna possível todo o resto; quer dizer, estamos mais preocupados com a mãe segurando o bebê em seus braços do que com a mãe alimentando o bebê.

Essa passagem aponta para o lugar por meio do qual Winnicott fala, além de apresentar a importância de suas contribuições ao campo psicanalítico. O entorno assume a dianteira das formulações winnicottianas, enquanto seu pensamento escancara a importância da dimensão relacional em nossa forma de ser e viver. Mas o que seria o cuidado, afinal? Não seria justamente a atenção que dispensamos e sentimos do outro?

Para Winnicott, o início da vida é marcado pela experiência de dependência absoluta, momento em que o bebê não pode prescindir de alguém que dele se ocupe e com ele se preocupe. Ao se deparar com a realidade resta-lhe, portanto, encontrar um ambiente suficientemente acolhedor e capaz de se adaptar a suas necessidades. O cuidado torna-se fundamental nessa travessia, e Winnicott, ao dar destaque à relação mãe-bebê, apresentou como essas primeiras relações participam da estruturação subjetiva.

Em A preocupação materna primária, Winnicott (1956/2000a) leva em conta o papel materno, apresentando o que considera uma etapa fundamental no contexto inicial de vida. Descreve esse momento como uma etapa de completa identificação da mãe com seu bebê, ainda em fase muito primitiva, que a faz viver uma devoção fora do comum. Em suas palavras:

Não acredito que seja possível compreender o funcionamento da mãe no início mesmo da vida do seu bebê sem perceber que ela deve alcançar esse estado de sensibilidade exacerbada, quase uma doença, e recuperar-se dele. (p. 401)

Essa disponibilidade de adaptação ao bebê permite que a mãe ofereça um ambiente suficientemente bom, fomentando um terreno fértil ao estabelecimento do ego a partir da experiência da "continuidade do ser". A linha de existência, que corresponde à constituição inicial do ego, é a primeira organização psíquica e deriva da possibilidade de superar as frustrações da vida sem sucumbir à angústia do aniquilamento. Sua tese pode ser assim resumida:

O fornecimento de um ambiente suficientemente bom na fase mais primitiva capacita o bebê a começar a existir, a ter experiências, a construir um ego pessoal, a dominar os instintos e a defrontar-se com todas as dificuldades inerentes à vida. (Winnicott, 1956/2000b, p. 404)

Portanto, o desenvolvimento inicial de um bebê, que repercute por toda a vida da criança, supõe que essas primeiras experiências relacionais sejam vividas a seu ritmo. Acreditamos, é importante frisar, que o agente de cuidado ultrapassa a figura materna, desde que seja alguém capaz de participar dessa complexa trama de acontecimentos 
oferecendo uma provisão ambiental compatível com as necessidades do bebê.

Em Teoria do relacionamento paterno-infantil (Winnicott, 1960/2007a), o ambiente de holding é apresentado como uma fase importante no processo de amadurecimento individual. Para Winnicott, o holding pode ser descrito como a provisão ambiental que antecede o momento que o bebê é capaz de viver com, também definida como uma forma de amor. A possibilidade de ser amado em um ambiente de cuidado seria, portanto, o que promove a sensação de segurança e uma experiência de integração, significativamente relevantes à constituição psíquica. Dessa maneira, a atitude do indivíduo com relação ao mundo e às experiências de vida dependem, em grande parte, da aquisição de uma confiança mínima em si, capaz de promover uma existência criativa e autônoma.

Ao longo do processo de amadurecimento que decorre, sobretudo, de uma conquista relacional, se dá um complexo trabalho psíquico. As experiências afetivas, marcadas pela presença sensível e implicada do outro, gradativamente transformam-se e, à medida que o meio mostra-se protetor, as conquistas vão se sofisticando. A capacidade de ficar só é destacada por Winnicott (1958/2007b) como uma experiência marcante nesse processo. Tomada como sinônimo de maturidade, ficar só é uma aquisição posterior, que decorrerá da experiência inicial vivida pelo bebê, e depois pela criança, de estar só na presença do outro.

Segundo Winnicott (1958/2007b), a situação é um paradoxo; pois a base da capacidade de ficar só reside nessa capacidade de ficar só na presença do outro. Ou seja, estar só é uma conquista decorrente da experiência inicial de confiança na presença de alguém, condição para que as necessidades individuais comecem a se definir. O bebê aprende a ficar só, na medida em que adquire a capacidade de ficar só na presença da mãe.

Pode se dizer que a relação com o id fortifica o ego quando ocorre em um contexto de relação com o ego. Aceitando isso, a compreensão da importância da capacidade de ficar só se segue naturalmente. É somente quando só (isto é, na presença de alguém) que a criança pode descobrir a sua vida pessoal própria. (p. 35)

Assim, a confiança na presença do outro tenderia a transformar essa experiência em uma vivência do ego, auxiliando a integração do bebê e transformando-a em parte de seu processo de constituição psíquica. A capacidade de ficar só, portanto, é uma expressão de que o indivíduo se estabeleceu como uma unidade e, por essa razão, está intimamente relacionada a sua maturidade emocional.

É preciso lembrar, contudo, que essa descoberta como pessoa separada do outro só se faz possível frente a um longo trabalho de acolhimento proporcionado pela sensibilidade acurada de outro indivíduo. O que nos permite afirmar que, ao preconizar a experiência relacional, Winnicott trabalha em um registro intersubjetivo, nos levando a pensar o cuidado como parte importante no processo de integridade física e psíquica.

Figueiredo (2009) propõe-se a pensar sobre uma teoria geral do cuidado por meio da leitura psicanalítica e acaba definindo o que chamou de uma "metapsicologia do cuidado". Para ele, a "presença reservada" e a "presença implicada" participam da vida reposicionando o homem em relação ao mundo e permite-nos dizer que o cuidado facilita que a criação de um sentido humano para as experiências.

Em sua formulação, desde a recepção do infante à vida adulta, nos depararíamos com agentes de cuidado pais, enfermeiros, médicos, professores, amigos - que, ao promoverem uma presença de acolhimento e sustentação, levariam a uma experiência de integração expressa pelo equilíbrio subjetivo e espontâneo. Em suas palavras:

Muitas vezes, cuidar é, basicamente, ser capaz de prestar atenção e reconhecer o objeto dos cuidados no que ele tem de próprio e singular, dando disso testemunho e, se possível, levando de volta ao sujeito sua própria imagem. (Figueiredo, 2009, p. 138)

Assim, o cuidado exerce um papel de ser condição de possibilidade para os eventos da vida. O destaque a essa atmosfera adequada de implicação e reserva às necessidades do outro não seria responsável apenas pela constituição de uma estruturação das dimensões do self, mas também tenderiam a promover o que há de mais simples e fundamental: a dimensão ética da existência.

\section{A Ética do cuidado em Psicanálise}

Uma das funções do cuidado seria desenvolver a capacidade cuidadora, em uma mutualidade de cuidados que culmina em uma atitude ética diante do outro e do mundo. Rocha (2012), em conferência intitulada Por uma clínica psicanalítica do Cuidado, desenvolve uma articulação entre as contribuições de Heidegger e a clínica psicanalítica retomando aspectos interessantes que podem ser pensados em relação ao compromisso ético da clínica. O autor nos apresenta, entre outras coisas, uma distinção fundamental entre a Sorge como Besorgen (ocupação) e a Sorge como Fürsorgen (preocupação, solicitude), que nos ajuda a rever a atitude analítica e suas relações com o cuidado.

Em uma clínica do cuidado, o ato de clinicar não se reduz a uma mera ocupação profissional, clinicar é dedicar-se aos clientes com preocupação, solicitude e desvelo. Desse modo, o desdobramento heideggeriano da Sorge (cuidado) em Besorgen (ocupação) e Fürsorgen (preocupação e solicitude) abre perspectivas novas e interessantes para uma melhor compreensão do cuidado clínico. (Rocha, 2012, p. 15)

Essa abertura, proporcionada por reflexões desse tipo, tem promovido contribuições significativas à clínica 
psicanalítica contemporânea. Em sua leitura sobre as interfaces entre a ontologia do cuidado em Heidegger e a clínica psicanalítica, Rocha (2012) acena para uma clínica eticamente comprometida com o outro, que estaria para além da mera condição de vigilância e atenção, uma clínica destinada a cuidar como forma de amar.

Nesse momento, parece-nos oportuno citar as contribuições de Sándor Ferenczi, destacando aqui como sua obra ajuda a pensar a ética do cuidado presente na clínica psicanalítica. Para tanto, consideramos a inovação promovida por ele ao trazer para o cerne da psicanálise conceitos como empatia e hospitalidade, destacando ainda a dimensão da criação compartilhada como um elemento fundamental do processo terapêutico. Isso porque a posição teórica de Ferenczi está marcada por uma convocação aos analistas para assumirem uma implicação técnica, como antes nunca visto nas teorizações psicanalíticas. Em suas formulações, o papel do analista no processo é explicitado e o encontro afetivo é elevado a uma estética necessária à vida subjetiva.

Apesar de não ter trabalhado diretamente com crianças, Ferenczi falou da infância em diferentes passagens, retomando-a ao discorrer sobre a vida psíquica, sobretudo, quando escreveu sobre os efeitos patógenos do trauma. Ao explicar sua busca por uma modificação na técnica, comentou sua relação com as crianças e sobre como se tornou um especialista nos casos difíceis:

Não tenho tido muito trato com crianças, em psicanálise, e eu mesmo me surpreendo por me defrontar agora, por um caminho muito diverso, com o problema da análise infantil. De fato, como cheguei a ele? Antes de responder a essa pergunta. Não é inútil participar-lhes, em poucas palavras, uma particularidade fez-me considerar os eventuais fracassos menos como consequência de uma "incurabilidade" do que da nossa própria inépcia, hipótese que me levou necessariamente a modificar a técnica nos casos difíceis em que era impossível obter êxito com a técnica habitual. (Ferenczi, 1931/2011e, p. 81)

Não é por acaso, portanto, que ao longo de sua obra muitos são os trabalhos em que já no título mencionam as crianças. Ao considerar o papel dos vínculos na constituição psíquica e desenvolver a importância da relação entre analista e analisando, Ferenczi cedo percebeu a necessidade de remontar às experiências infantis como via de acesso não apenas ao mundo intrapsíquico, mas também como elemento fundamental para a compreensão do mecanismo da traumatogênese. Foi assim que desenvolveu uma técnica sensivelmente cuidadosa com seus pacientes e conseguiu analisar os aspectos relativos às experiências iniciais do bebê, trazendo ricas contribuições à compreensão da constituição de si.

Em seus últimos textos, podemos encontrar um debate sobre a técnica na clínica psicanalítica, cuja ênfase nos aproxima do que estamos chamando de ética do cuidado.
É o caso de textos como: A adaptação da família à criança (1928), A criança mal acolhida e sua pulsão de morte (1929), Princípio de relaxamento e neocatarse (1929), Análises de crianças com adultos (1931) e Confusão de línguas entre adultos e crianças (1933). Sobre este período da obra ferencziana, Balint (1967/2011, p. XXIII) afirma:

Com base em suas experiências, Ferenczi, no seu período, chegou à conclusão de que um recurso honesto à afeição e à gentileza sinceras podia ser autorizado nos casos em que suas interpretações mostraram ser ineficazes e inúteis.

Desde então, a mudança técnica foi expressiva e seu impacto é visto na clínica psicanalítica por cada um daqueles que, ao decidir trabalhar com a clínica de pacientes difíceis, tem a oportunidade e a disponibilidade de se encontrar com a obra de Ferenczi. Isso porque o psicanalista húngaro foi capaz de questionar o estabelecido e, a partir de uma clínica afetivamente implicada com o paciente, propor elementos fundamentais para pensarmos uma clínica do cuidado. Por convicção, acreditava que a confiança no espaço terapêutico, fundamental ao processo, decorria da maneira sensível que o analista encontrava para estar com seu paciente.

Em Elasticidade da técnica psicanalítica (Ferenczi, 1928/2011b), ele adotou conceitos como tato e empatia para falar sobre a flexibilidade necessária ao trabalho analítico. Ao retomar esses conceitos, Ferenczi convoca os analistas a trabalharem de forma diferente com seus analisandos. Comentando sua conceituação, se interroga: "Mas o que é o tato? A resposta a esta pergunta não nos é difícil. O tato é a faculdade de "sentir com (Einfühlung)" (p. 31). A simplicidade dessa definição nos mostra a complexidade do conceito. Ser capaz de "sentir com" ultrapassa a possibilidade de colocar-se no lugar do outro ou de identificar-se com seu sofrimento; é ter a disponibilidade de se oferecer junto do paciente para viver alguns de seus sentimentos mais primitivos, uma experiência de mutualidade, mas que não deixa de estar ancorada na capacidade do analista em reconhecer sua posição na relação.

A metáfora utilizada por Ferenczi é precisa: ao analista caberia portar-se como uma tira elástica, prestando-se ao papel de "joão-teimoso", sendo capaz de distanciar-se e aproximar-se a partir dos afetos experimentados com o paciente. Essa disposição para "ceder às tendências do paciente, mas sem abandonar a tração na direção de suas próprias opiniões" (Ferenczi, 1928/2011b, p. 37) é papel fundamental da técnica.

O que nos permite pensar que para Ferenczi, a ética do cuidado na psicanálise é proporcional à elasticidade da técnica, ou seja, é possível supor que somente a partir de uma elasticidade técnica por parte do analista seria possível ao analisando experimentar uma via de acesso à "ética do cuidado" em psicanálise. Contudo, é importante que se diga: por si só isso não se faz suficiente. Para além da empatia, seriam necessárias ainda a hospitalidade e a 
saúde do analista para que os princípios da ética do cuidado (Kupermann, 2009) possam se fazer presentes na prática psicanalítica. Soma-se a isso a compreensão ferencziana de que a técnica não deve ser reduzida a um trabalho meramente intelectual do analisando, mas que possa ser considerada pela via da afetação.

A dimensão da hospitalidade é apresentada como fundamental na constituição psíquica do bebê; ela caracteriza-se pela maneira como o ambiente recepciona a criança que chega ao mundo e adapta-se às necessidades do novo membro. Essa noção traz a ênfase no ambiente e nas experiências intersubjetivas, discutindo como a criança mal acolhida não tem a possibilidade de desenvolver suas expressões criativas. Na clínica, para que isso se dê, é fundamental preconizar um acolhimento caloroso como ponto de partida para uma análise, assim como faz uma família quando recebe um novo hóspede. Essa adaptação ativa do ambiente psicanalítico a um novo paciente é o que Ferenczi definiu como hospitalidade.

Outro princípio destacado por Ferenczi reside na exigência de 0 analista realizar sua higiene particular (Ferenczi, 1930/2011b, p. 40), ou seja, de ele ser capaz de encontrar formas de cuidar de si, preservando sua saúde emocional, cuja importância levou o autor a defender a análise profunda do analista como uma segunda regra fundamental da psicanálise. A saúde do analista, portanto, mais do que uma condição para o trabalho, pode ser tomada como um princípio norteador de uma ética do cuidado, na medida em que corresponde a um aspecto basilar para o bom exercício técnico de sua função.

\section{A dimensão intersubjetiva}

Transgredindo alguns dos conselhos técnicos de Freud, Ferenczi foi crítico à ortodoxia freudiana, mas não deixou de valorizar os pressupostos fundamentais da psicanálise. Não sendo nosso propósito aqui desenvolver todas as contribuições deste autor à técnica em psicanálise, gostaríamos de destacar aquilo que consideramos um aspecto importante em sua leitura ética da clínica, quiçá, mais um dos princípios da ética do cuidado: a dimensão da intersubjetividade. Nessa concepção, a vivência afetiva - enquanto leitura do fator emocional - é vista como estando além das convicções e das conquistas intelectuais do paciente. Seria a abertura para esse campo intersubjetivo, aquilo que nos permite pensar na ética em psicanálise, tal como afirma Coelho (2004) ao falar sobre a obra de Ferenczi:

Não há como recusar que seu trabalho amplia o horizonte ético implicado no trabalho analítico. Postular que sentimentos e ideias de analista e paciente podem entrelaçar-se e que o outro à minha frente não é "uma representação do meu ego", mas um ser real com quem posso me identificar, explicita um reconhecimento do outro em termos éticos, em uma amplitude até então pouco valorizada nos textos psicanalíticos. (p. 83)
Nesse contexto, a ênfase do trabalho psicanalítico residiria na qualidade de "sentir com" o paciente, cujos fundamentos estariam assentados no argumento de uma ética psicanalítica que dirige seu olhar aos sofrimentos do acontecer psíquico, decorrente de uma "posição afetiva flutuante do analista diante do analisando" (Maia, 2009). Essa disponibilidade afetiva - preconizada pela hospitalidade, pela empatia e promovida pela condição de saúde do analista - introduziria a dimensão do cuidado no registro de uma ética psicanalítica. Assim, a ética do cuidado em psicanálise pode ser pensada como uma ética da afeição, cujo compartilhamento de vivências criativas entre o analista e o analisando assume a dianteira do compromisso técnico também pela via sensível da elaboração (Kupermann, 2010) na experiência intersubjetiva.

Essa dimensão intersubjetiva, que encontramos também em Freud, conquistou um acento diferente nas obras de Ferenczi e de Winnicott. A concepção de transferência foi se transformando frente aos desafios clínicos colocados pelos novos contextos e formas de sofrimento que emergiam, promovendo com isso novos estilos de psicanalisar. Ainda sobre o papel desempenhado por Sándor Ferenczi nessas redescrições, Kupermann (2008) afirma:

A "inovação" de Ferenczi, segundo a sua própria avaliação, foi resgatar da regra fundamental a dimensão de liberdade - perdida em grande parte ao longo do processo de institucionalização da psicanálise. (p. 94)

Como sabemos, Winnicott, apoiado em Ferenczi (Grãna, 2007) deu continuidade às reflexões sobre o manejo psicanalítico regido por esses princípios éticos. Em sua significativa contribuição à clínica psicanalítica com crianças é possível encontrar uma técnica que valoriza a comunicação explícita e implícita, mas, sobretudo, preocupa-se com a dimensão da experiência subjetiva presente no ofício do psicanalista.

Ao procederem assim, esses dois psicanalistas enfatizaram o desenvolvimento da noção de sensibilidade, fundamental para a criação de uma clínica psicanalítica que toma o cuidado como combustível para um exercício psicanalítico ético e criativo capaz de promover um contraponto ao discurso patologizante na infância. ${ }^{2}$ Referimo-nos aqui ao movimento contemporâneo de homogeneização dos comportamentos tidos como desviantes na infância, que tende a transformar o sofrimento das crianças, e suas diferenças, em diagnósticos, produzindo uma forma discursiva normatizadora que se apresenta por padronizar e etiquetar as mais variadas expressões humanas.

Enquanto coube a Ferenczi (1933/2011f) problematizar o acolhimento do infantil na análise a partir de sua compreensão de que uma "linguagem de ternura" está presente na vida da criança, a Winnicott (1960/2007a) coube

2 Para uma análise mais completa desse problema, sugerimos a leitura de França (2014). 
uma abertura para uma leitura do sofrimento infantil sob a consideração das relações entre a vida intrapsíquica e o papel do ambiente na constituição subjetiva.

O impacto do ambiente no desenvolvimento humano como axioma da obra winnicottiana movimentou também a forma de proceder do analista no setting. É sabido que, ao se aventurar na clínica de crianças, a psicanálise precisou reformular sua técnica. Analisar crianças, portanto, implicava mais do que tomar a interpretação como única via de acesso ao inconsciente, tal como propuseram nomes como Melanie Klein (1997) e Anna Freud (1971), era necessário avançar. Coube a Winnicott apresentar uma formulação do brincar que ultrapassava a expressão simbólica do ato, destacando a mutualidade que a atividade compartilhada proporciona. Para ele:

A psicoterapia se efetua na sobreposição de duas áreas do brincar, a do paciente e a do terapeuta. A psicoterapia trata de duas pessoas que brincam juntas. Em consequência, onde o brincar não é mais possível, o trabalho efetuado pelo terapeuta é dirigido então no sentido de trazer o paciente de um estado em que não é capaz de brincar para um estado em que o é. (Winnicott, 1975, p. 59)

Ao explorar a natureza humana, Winnicott nos mostra como a dimensão do viver estaria em uma zona intermediária entre o indivíduo e o meio ambiente, o que implica considerar a potencialidade existente na própria experiência da brincadeira. O que ele enfatiza é a criatividade presente no ato de brincar e não os conteúdos nele dispostos, ou seja, para além dos elementos presentes na brincadeira, interessa que a criança brinque, pois essa vivência por si só já comporta aspectos fundamentais ao desenvolvimento emocional da criança. Winnicott (1975) assim resume esse percurso: "Há uma evolução direta dos fenômenos transicionais para o brincar, do brincar para o brincar compartilhado, e deste para as experiências culturais" (p. 76).

As formulações que decorreram dessa compreensão winnicottiana, promoveram um entendimento novo sobre a constituição subjetiva das crianças levando o par que provê cuidado (indivíduo-ambiente) a assumir um lugar fundamental na trama subjetiva. Em sua obra, a confiança proporcionada por um ambiente acolhedor e atento às necessidades do bebê desde seu nascimento é tomada como expressão emblemática do que é necessário também ao processo analítico, leia-se a capacidade de adaptação do analista ao ritmo de seu analisando. Com as crianças, portanto, isso não é diferente. O psicanalista de crianças precisa ser capaz de, como uma "mãe suficientemente boa", oferecer a preocupação e o continente necessários para o estabelecimento de um espaço lúdico onde a vida criativa possa encontrar expressão. O fracasso de sua vitalidade e de suas qualidades essenciais de cuidados reais tende a impedir ou interromper o desenvolvimento da criança, assim como acontece quando o holding não é suficientemente proporcionado ao bebê.

Seguindo viagem com Winnicott, percebemos que a clínica psicanalítica de crianças, ao valorizar a experiência do cuidado nas relações intersubjetivas, objetiva promover um terreno fértil à apropriação criativa de si. Nessa travessia rumo ao amadurecimento individual - desde que o ambiente exerça sua função - caberia à criança e a seus pais responder apenas à vida a seu tempo, sem se mostrar satisfeito com aquilo que possa vir a reduzir sua alteridade a um padrão socialmente preestabelecido.

Plastino (2009), ao discorrer sobre a dimensão constitutiva do cuidar, diz que: "Donald Winnicott permitirá pensar a emergência de uma ética enraizada na dinâmica afetiva dos processos espontâneos (naturais no sentido específico de Winnicott)" (p. 60). A ação genuína de estar com o outro e estar no mundo dependeria, portanto, das tendências que favoreceriam a emergência espontânea para a vida. $\mathrm{O}$ autor explica a complexidade do processo de constituição humana assinalando dois aspectos fundamentais para sua emergência: o outro da cultura e o movimento espontâneo do sujeito.

Isso nos permite afirmar que encontrar a justa medida no cuidado com a criança, longe de ser invasiva, tampouco insuficiente, garantiria um ambiente propício a uma existência menos assujeitada às práticas de generalização ou submissão às regras e às coerções externas, tão comuns ao processo de inserção na comunidade. Para Mizrahi (2010):

O contraste entre uma concepção moral como assujeitamento do indivíduo a certas regras e coerções externas, e esta outra, proposta por Winnicott, que pode ser entendida como ligada ao cuidado consigo mesmo - que vem a constituir o ego - nos leva a apreciar um modo de subjetivação muito distinto daquele promovido pelo regime do biopoder. ... Bem distintamente, o governo interno constituído pelo ego winnicottiano é um governo de si que não regula, nem exerce coerção, mas cuida e traz satisfação. (p. 122)

Essa passagem nos permite destacar o papel do cuidado de si, tão esquecido em nossos tempos, como possibilidade de acesso a uma vida marcada pelo compromisso de alargamento e mobilidade da subjetividade. Para Costa (2007):

Em Winnicott, mais do que em Freud, o caráter de "ação" da conduta ética emerge com uma nitidez ineludível. Nele, o foco da análise se desloca da relação entre ética e norma moral para $o$ ato criador, no qual o fundamento é a parceria com o outro na construção da realidade transicional. (p. 99)

Esse destaque à noção de parceria na clínica psicanalítica é um aspecto marcante no trabalho com 
crianças, especialmente, porque o desenvolvimento infantil depende das primeiras experiências de trocas e cuidados. Zornig (2010), ao refletir sobre a ética do cuidado na primeira infância, fala do papel fundamental do agente cuidador - seja ele a mãe, o pai, membros da família, da comunidade ou das creches. Sua pesquisa apresenta a afirmação da importância dessa parceria desde os primeiros tempos de vida, analisando a função de sustentação e continência promovida pelo cuidador em sua ação. A discussão da presença afetiva do outro é novamente ressaltada aqui, nos levando a concluir que a ética do cuidado na psicanálise, sobretudo com crianças, está relacionada à oferta de uma presença implicada cujas trocas possam promover a potencialização do que lhe é inato (como a criatividade e a capacidade de reestabelecimento) e desenvolver as que estão em formação.

O estilo de psicanalisar, portanto, toma a cena na clínica psicanalítica contemporânea, enquanto a ética psicanalítica, podemos assim dizer, encontra na confiança, uma possibilidade de existência. Mais do que mero exercício técnico e interpretativo, a psicanálise cada vez mais se aproxima da experiência do cuidado que oferta uma presença sensível (Kupermann, 2008) ao sujeito e é capaz de promover uma criação ética de si (Costa, 2007).

Ao pensar na clínica psicanalítica com crianças é importante não perdermos de vista que o excesso de ocupação dos pais com seus filhos e a preocupação exaltada em todos os seus momentos de vida, longe de garantir uma existência melhor, pode ser o primeiro passo para uma ausência de cuidados, no sentido que estamos trabalhando aqui. Na clínica psicanalítica com crianças aprendemos que o jogo compartilhado é "sempre uma experiência criativa, uma experiência de continuidade espaço-tempo, uma forma básica de viver" (Winnicott, 1975, p. 75).

\section{Considerações finais}

É nesse caminho que a clínica do cuidado apresenta-se como uma alternativa ética à psicanálise de crianças. Para nós, o exercício clínico mostra-se comprometido com a mobilidade da moldura subjetiva das crianças, assim como com a apropriação criativa que elas podem fazer de si, desde que possa ser norteado pela dimensão afetiva contida em uma técnica sensível e empática, tal como propõem Ferenczi (1933/2011f), e Winnicott (1953/2000a).

A liberdade criativa das crianças poderá ser desenvolvida sempre que a clínica psicanalítica puder funcionar como um espaço de favorecimento à constituição psíquica a partir da intersubjetividade e como um espaço potencial ofertado pela experiência do brincar. A ética do cuidado configura-se como a dimensão sensível do encontro entre analista e analisando na clínica, cujos princípios éticos estariam assentados em um manejo técnico que considere a hospitalidade, a empatia e o tato, sem desconsiderar, como prezou Ferenczi, a higiene pessoal do analista. A psicanálise, portanto, se apresentaria como uma reserva ética na contemporaneidade (Kupermann, 2009b) capaz de oferecer ao trabalho dos psicanalistas um exercício afetivamente implicado norteando, também, uma ética do cuidado na clínica com crianças.

A clínica psicanalítica oferece às crianças uma possibilidade de cuidado em uma linguagem diferente daquela pensada e proposta pela ordem médica e comportamental. Nela, a apropriação criativa do mundo (Mizrahi, 2010) é ponto de partida e também de chegada, mostrando como a dimensão relacional é parte constitutiva da experiência subjetiva. Apropriar-se do mundo significa poder experimentar essa constituição permanentemente marcada pelo ato criador, capaz de favorecer o desenvolvimento de uma vida autônoma e genuína.

\section{For an ethic of care in child psychoanalysis}

Abstract: Reflecting on the role of care in psychic constitution, this article discusses the fundamental aspects to think about the psychoanalytic treatment of children, marked by an ethical exercise. The clinical style of Winnicott and Ferenczi, taken as reference, favors the proposition that the intersubjective dimension shows up as a central element to the ethics of care in psychoanalysis, which may help to put the practices of care in childhood in motion.

Keywords: child care, ethics, child psychoanalysis.

\section{Par une éthique du soin dans la Psychanalyse des enfants}

Résumé: En réfléchissant sur le rolê du soin dans la constitution psychique, cet article aborde les aspects fondamentaux concernants le sujet du traitement psychanalytique des enfants, qui est marqué par un exercice éthique. Le style clinique de Winnicott et Ferenczi, pris comme référance, mettre en évidence l'idée selon laquelle la dimension intersubjective se présente comme un élément central de l'éthique du soin de la psychanalyse, peuvent aider à faire avancer les pratiques du soin dans l'enfance.

Mots-clés: soin, éthique, psychanalyse des enfants. 


\section{Por una ética de cuidado en el Psicoanálisis del niño}

Resumen: A través de la reflexión sobre la función de "cuidado" en la constitución psíquica, este artículo discute los aspectos fundamentales para que se piense el tratamiento psicoanalítico de niños, marcado por un ejercicio ético. El estilo clínico de Winnicott y Ferenczi, tomado como referencia, favorece la proposición de que la dimensión intersubjetiva se muestra como un elemento central a la ética de cuidado en Psicoanálisis, pudiendo contribuir para el movimiento de las prácticas de cuidado en la infancia.

Palabras clave: cuidado del niño, ética, psicoanálisis del niño.

\section{Referências}

Balint, M. (2011). Introdução: as experiências técnicas de Sándor Ferenczi: perspectivas para uma evolução futura. In S. Ferenczi, Psicanálise IV (pp. XVII-XXVI). São Paulo, SP: Martins Fontes. (Trabalho original publicado em 1967).

Coelho Jr., N. E. (2004). Ferenczi e a experiência da Einfühlung. Ágora: Estudos em Teoria Psicanalítica, 7(1), 73-85. Recuperado de http://www.scielo. br/scielo.php?script=sci_arttext\&pid=S 1516 $14982004000100005 \& \operatorname{lng}=$ en \&tlng=pt.\%2010.1590/ S1516-14982004000100005

Costa, J. F. (2007). Criatividade, transgressão e ética. In J. F. Costa, O risco de cada um: e outros ensaios de psicanálise e cultura (pp. 83-100). Rio de Janeiro, RJ: Garamond.

Dunker, C. I. L. (2011). Estrutura e constituição da clínica psicanalítica: uma arqueologia das práticas de cura, psicoterapia e tratamento. São Paulo, SP: Annablume.

Ferenczi, S. (2011a). A adaptação da família à criança. In S. Ferenczi, Psicanálise IV (pp. 1-15). São Paulo, SP: Martins Fontes. (Trabalho original publicado em 1928)

Ferenczi, S. (2011b). Elasticidade da técnica psicanalítica. In S. Ferenczi, Psicanálise IV (pp. 29-42). São Paulo, SP: Martins Fontes. (Trabalho original publicado em 1928)

Ferenczi, S. (2011c). A criança mal acolhida e a pulsão de morte. In S. Ferenczi, Psicanálise IV (pp. 1-15). São Paulo, SP: Martins Fontes. (Trabalho original publicado em 1929)

Ferenczi, S. (2011d). Princípio de relaxamento e neocatarse. In S. Ferenczi, Psicanálise IV (pp. 1-15). São Paulo, SP: Martins Fontes. (Trabalho original publicado em 1930)

Ferenczi, S. (2011e). Análises de crianças com adultos. In S. Ferenczi, Psicanálise IV (pp. 79-115). São Paulo, SP: Martins Fontes. (Trabalho original publicado em 1931)

Ferenczi, S. (2011f). Confusão de língua entre os adultos e a criança. In S. Ferenczi, Psicanálise IV (pp. 1-15). São Paulo, SP: Martins Fontes. (Trabalho original publicado em 1933)

Figueiredo, L. C. (2009). A metapsicologia do cuidado. In L. C. Figueiredo, As diversas faces do cuidar: novos ensaios de psicanálise contemporânea (pp. 131-151). São Paulo, SP: Escuta.

França, R. M. P. (2014). A nau das crianças-problema: entre a patologização do sofrimento psíquico na infância e a ética do cuidado na psicanálise. Dissertação (Mestrado) - UNICAP, Recife, PE.
Freud, S. (1969). Inibições, sintomas e ansiedade. In S. Freud, Edição standard brasileira das obras psicológicas completas de Sigmund Freud (J. Salomão, trad., Vol. 20, pp. 95-200). Rio de Janeiro, RJ: Imago. (Trabalho original publicado em 1926).

Freud, A. (1971). Infância normal e patológica. Rio de Janeiro: Zahar.

Graña, R. B. (2007). Origens de Winnicott: ascendentes psicanaliticos e filosóficos de um pensamento original. São Paulo: Casa do Psicólogo.

Klein, M. A psicanálise de crianças. Rio de Janeiro: Imago, 1997.

Kupermann, D. (2008). Presença sensivel: cuidado e criação na clínica psicanalítica. Rio de Janeiro, RJ: Civilização Brasileira.

Kupermann, D. (2009). Figuras do cuidado na contemporaneidade: testemunho, hospitalidade e empatia. In M. S. Maia (Org.), Por uma ética do cuidado (pp. 185-204). Rio de Janeiro, RJ: Garamond.

Kupermann, D. (2010). A via sensível da elaboração. Caminhos da clínica psicanalítica. Cadernos de Psicanálise, Círculo Psicanalítico RJ, 23, 3145. Recuperado de http://www.freudiana.com.br/ documentos/CADERNOS-DE-PSICANALISE_A-viasensivel-Daniel\%20Kupermann.pdf

Maia, M. S. (2009). O tato do analista. Memória da psicanálise 3: Sándor Ferenczi: a ética do cuidado (pp. 37-43). São Paulo, SP: Duetto.

Mizrahi, B. G. (2010). A vida criativa em Winnicott: um contraponto ao biopoder e ao desamparo no contexto contemporâneo. Rio de Janeiro: Garamond.

Plastino, C. A. (2009). A dimensão constitutiva do cuidar. In Maia, M. S. (Org.), Por uma ética do cuidado. Rio de Janeiro, RJ: Garamond.

Rocha, Z. (2011). A ontologia Heideggeriana do cuidado e suas ressonâncias clínicas. Síntese - Revista de Filosofia, 38(120), 71-90. Recuperado de http://faje.edu.br/ periodicos2/index.php/Sintese/article/view/1037/1461

Rocha, Z. (2012). Para uma clínica psicanalítica do cuidado. Conferência pronunciada no XIX Congresso do Círculo Brasileiro de Psicanálise e XXVI Jornada do Círculo Psicanalítico de Pernambuco, Recife.

Zornig, S.A. (2010). Reflexões sobre uma ética do cuidado na primeira infância. Primórdios-CPRJ, 
1(1), 15-26. Recuperado de http://www.cprj.com.br/ primordios/15-26_reflexoes.pdf

Winnicott, D. D. (1975). O brincar e a realidade. Rio de Janeiro, RJ: Imago.

Winnicott, D. W. (2000a). Tolerância ao sintoma em pediatria: relato de um caso. In D. W. Winnicott, $O$ ambiente e os processos de maturação: estudos sobre a teoria do desenvolvimento emocional (pp. 168-186). Porto Alegre, RS: Artes Médicas. (Trabalho original publicado em 1953)

Winnicott, D. W. (2000b). A preocupação materna primária. In D. W. Winnicott, $O$ ambiente e os processos de maturação: estudos sobre a teoria do desenvolvimento emocional (pp. 399-405). Porto Alegre, RS: Artes Médicas. (Trabalho original publicado em 1956)

Winnicott, D. W. (2005). Influências de grupo e a criança desajustada: o aspecto escolar. In D. W. Winnicott, Privação e delinquência (pp. 215-226). São Paulo, SP: Marins Fontes. (Trabalho original publicado em 1955)

Winnicott, D. W. (2007a). Teoria do relacionamento paternoinfantil. In D.W. Winnicott, $O$ ambiente e os processos de maturação (pp. 38-54). Rio de Janeiro, RJ: Imago. (Trabalho original publicado em 1960)

Winnicott, D. W. (2007b). A capacidade para estar só. In D. W. Winnicott, $O$ ambiente e os processos de maturação (pp. 31-37). Rio de Janeiro, RJ: Imago. (Trabalho original publicado em 1958)

Recebido: 27/05/2014

Revisado: $27 / 12 / 2014$

Aceito: 05/01/2015 